\title{
EFFECT OF MOLECULAR ANISOTROPY ON THE INTENSITY AND DEGREE OF POLARIZATION OF LIGHT SCATTERED FROM MODEL ATMOSPHERES
}

(NASA-TA-X-70879) EFFECT OF MOLECULAR ANISOTROPY ON THE INTENSITY AND DEGREE OF POLARIZATION OE. LIGHT SCATTERED FROH MODEL ATMOSPHERES (HASA) $28 \mathrm{p} \mathrm{HC} \$ 3.75$ CSCL $20 \mathrm{~F}$ $63 / 47 \begin{aligned} & \text { Unclas } \\ & 20429\end{aligned}$

\section{OM P. BAHETHI ROBERT S. FRASER}
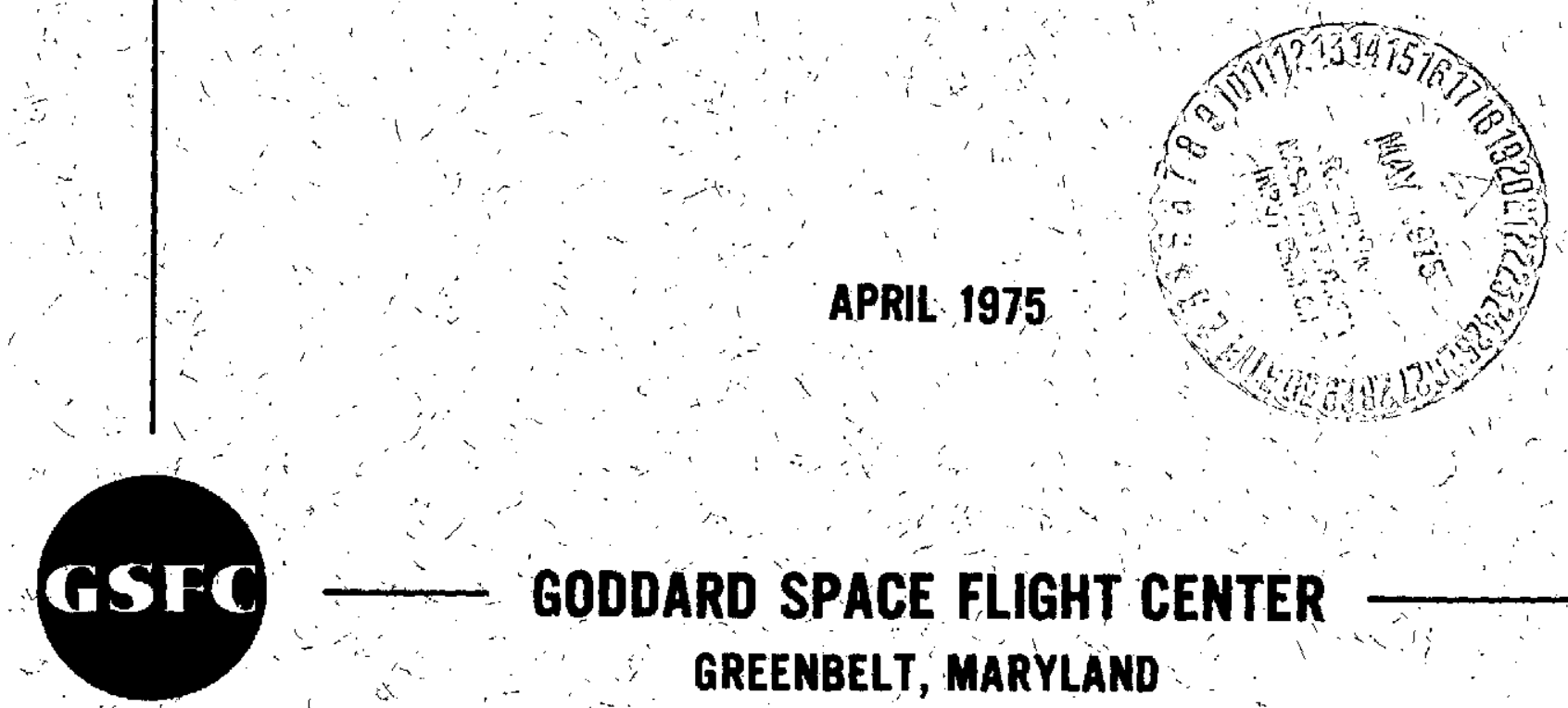

GODDARD SPACE FLIGHT CENTER GREENBELT, MARYLAND 


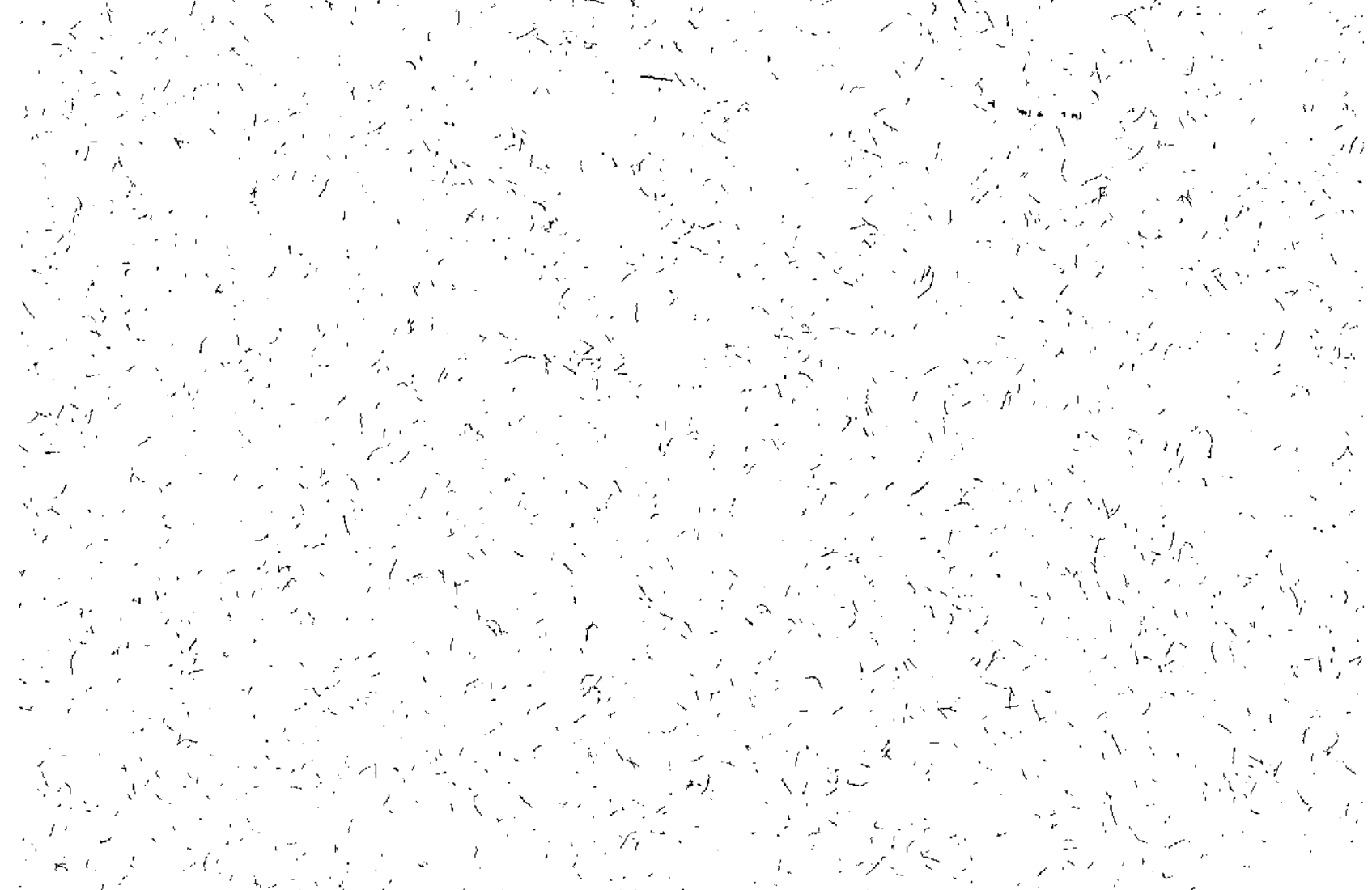

For information concerning availability of this document contact:-

Technical Information Division, Code 250

Goddard Space Flight Center

Greenbelt, Maryland 20771

\section{(Telephone 301-982-4488)}




\title{
EFFECT OF MOLECULAR ANISOTROPY ON THE INTENSITY AND DEGREE OF POLARIZATION OF LIGHT SCATTERED FROM MODEL ATMOSPHERES
}

\author{
Om P. Bahethi
}

Robert S. Fraser

April 1975 
CONTENTS

Page

ABSTRACT ....................... v

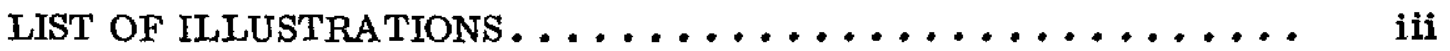

INTRODUCTION .......................... 1

PHASE MATRIX AND OPTICAL THICKNESS $\ldots \ldots \ldots \ldots \ldots \ldots 2$

MODELS AND COMPUTATIONAL DETAILS ........... 4

RESULTS AND DISCUSSION $\ldots \ldots \ldots \ldots \ldots \ldots \ldots \ldots \ldots \ldots$

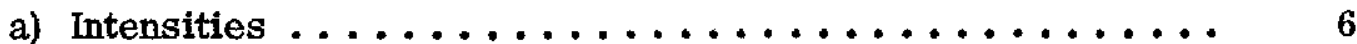

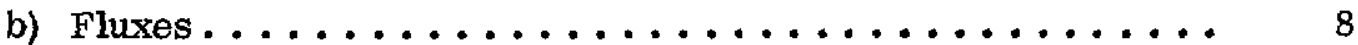

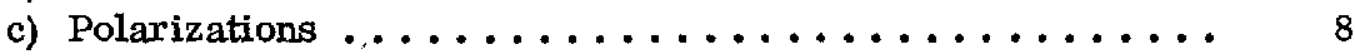

d) Neutral Points....................... 10

RESULTS FOR PARTIAL CORRECTION DUE TO MOLECULAR

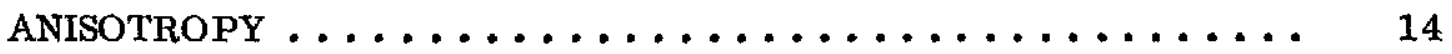

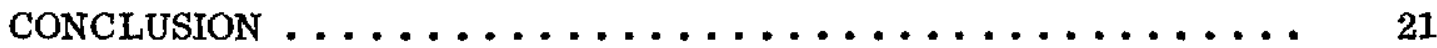

REFERENCES....................... 22

LIST OF ILLUSTRATIONS

Figure $\quad$ Page

1 An atmospheric model of the amount of ozone (solid line) and the total number of particulates in one square centimeter (dashed line) of a vertical column above a given level. The total ozone amount in a vertical column above sea level is $0.316 \mathrm{~atm}-\mathrm{cm}$ and the total number of particulates is $4.91 \times 10^{8} \mathrm{~cm}^{-2} \ldots \ldots \ldots \ldots \ldots \ldots \ldots \ldots$

2 The degree of polarization of light leaving the top of the atmosphere for various models. Wavelength $\lambda=0.55 \mu \mathrm{m}$; solar zenith $\theta_{0}=60^{\circ}$; ground reflectivity $\mathrm{A}=0.0$. Curve $\mathrm{E}$ refers to a model that is the same as model $D$, except for

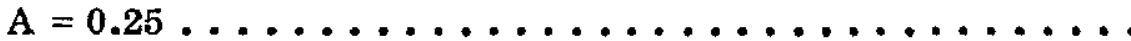

3 The degree of polarization of skylight at the bottom of atmosphere for the same conditions given in Figure 2..... 


\section{LIST OF ILLUSTRATIONS (Continued)}

Figure

4 The degree of polarization of light leaving the top of the atmosphere for various models. Wavelength $\lambda=0.55 \mu \mathrm{m}$; solar zenith $\theta_{0}=40^{\circ}$. Curves $A^{\prime}, B^{\prime}, C^{\prime}, D^{\prime}$ and $E^{\prime}$ are similar to those of Figure 2 except the correction due to molecular anisotropy is included only in the Rayleigh scattering phase matrix. The Rayleigh scattering optical thickness is 0.0980 in all these models ...........

5 The degree of polarization of skylight at the bottom of the atmosphere for the same conditions given in Figure $4 \ldots$. 


\title{
EFFECT OF MOLECULAR ANISOTROPY ON THE INTENSITY AND DEGREE OF POLARIZATION OF LIGHT SCATTERED FROM MODEL ATMOSPHERES \\ OM P. Bahethi \\ Computer Sciences Corporation \\ Robert S. Fraser \\ Atmospheric and Hydrospheric Applications Division, GSFC
}

\begin{abstract}
Computations of the intensity, flux, degree of polarization, and the positions of neutral points are presented for models of the terrestrial gaseous and hazy atmospheres by incorporating the molecular anisotropy due to air in the Rayleigh scattering optical thickness and phase matrix. It is found that the molecular anisotropy causes significant changes in the intensity, flux and the degree of polarization of the scattered light. The positions of neutral points do not change significantly. However, if the Rayleigh scattering optical thickness is kept constant and the molecular anisotropy factor is included only in the Rayleigh phase matrix, the flux does not change, the intensity changes by a small amount; but the changes in the degree of polarization are still significant. The change in the positions of neutral points is also very small.
\end{abstract}




\section{EFFECT OF MOLECULAR ANISOTROPY ON THE INTENSITY AND DEGREE OF POLARIZATION OF LIGHT SCATTERED FROM MODEL ATMOSPHERES}

\section{INTRODUCTION}

In recent years there has been a renewal of interest in employing degree of polarization measurements (Unz 1969; Rao et al., 1973) of scattered light to obtain information about the sizes and indices of refraction of atmospheric particulates. Professor Sekera (1957) had suggested that global studies of atmospheric turbidity and aerosols can be made from spacecraft by making measurements of polarization characteristics of scattered airlight. He proposed to derive aerosol parameters by comparing the measurements with a library of values computed from models of the atmosphere with various aerosol parameters. In addition, Sekera (1956) had also shown that both the degree of polarization and the positions of the neutral points of the skylight incident on the ground are related to the atmospheric turbidity.

A large number of computational schemes are available for studying the effect of aerosols on the polarization characteristics of scattered sunlight (Braslau and Dave, 1973; Plass and Kattawar, 1972; Kattawar, Plass and Catchings, 1973; Hansen, 1971; Herman and Browning, 1965). Generally, it is assumed that the effect of molecular anisotropy on the polarization characteristics of scattered light is small and is partially accounted for by increasing the Rayleigh optical thickness according to the correct theory. Molecular anisotropy, besides changing the Rayleigh optical thickness, leads to a change in the scattering phase matrix as well. It is thus essential to incorporate the changes due to molecular anisotropy in the optical thickness as well as the phase matrix to make an accurate study of the radiative transfer problem.

Dave (1964) has emphasized that the molecular anisotropy effect should be included in the radiative transfer studies of thin Rayleigh atmospheres. Schiffer (1972) has studied the polarization characteristics of skylight for Rayleigh atmospheres by incorporating molecular anisotropy in the Rayleigh phase matrix only. Hansen and Hovenier (1974) have included the effect of molecular anisotropy in the determination of the atmospheric pressure at the top of the clouds of Venus.

In this study we include the effect of molecular anisotropy in both the optical thickness and the phase matrix. Also, we analyze the consequences of including the anisotropy in just the phase matrix. The intensity, flux, degree of polarization, and positions of the neutral points are computed for sunlight scattered from the top and the base of two model atmospheres: a Rayleigh atmosphere and a terrestrial atmosphere that includes aerosols. The effect of the surface albedo, but not of the solar zenith angle, is also studied. 
Chandrasekhar (1960) has derived an expression for the phase matrix for scattering by a random aggregate of anisotropic molecules. The phase matrix $\underline{R}(\Theta)$ relates the Stokes parameters for the incident and scattered light as follows:

$$
\underline{I}^{s} \sim \frac{\sigma}{4 \pi} \underline{R}(\Theta) \underline{\mathbf{I}}
$$

Here $I^{\mathrm{s}}$ represents the four component Stokes matrix ( $\left(\mathrm{I}_{\ell}^{\mathrm{s}}, \mathrm{I}_{\mathrm{r}}^{\mathrm{s}}, \mathrm{U}^{\mathrm{s}}\right.$, and $\mathrm{V}^{\mathrm{s}}$ ) of the scattered light. $I\left(I_{\ell}, I_{r}, U, V\right)$ is the Stokes matrix for the incident light. Chandrasekhar (1960) defines both sets of Stokes parameters $I^{S}$ and I. $\sigma$ is the average scattering cross-section per air molecule and is given by

$$
\sigma=\frac{8 \pi^{3}}{3} \frac{\left(m^{2}-1\right)^{2}}{\lambda^{4} N^{2}} \frac{\left(6+3 \rho_{n}\right)}{\left(6-7 \rho_{n}\right)}
$$

$m$ is the index of refraction of air, $N$ is the molecular number density, and the depolarization factor $\rho_{\mathrm{n}}$ is defined as:

$$
\rho_{\mathrm{n}}=\frac{\mathrm{I}_{\ell}^{s}}{\mathrm{I}_{\mathrm{r}}^{\mathbf{s}}} ;
$$

here, $I_{\ell}^{s}$ and $I_{r}^{s}$ are the intensities of light scattered perpendicularly to the incident beam, which is unpolarized. The scattering phase matrix $\underline{R}(\Theta)$ is given by

$\underline{\mathrm{R}}(\Theta)=\frac{3}{2(1+2 \gamma)}\left(\begin{array}{cccc}\cos ^{2} \Theta+\gamma \cdot \sin ^{2} \Theta & \gamma & 0 & 0 \\ \gamma & 1 & 0 & 0 \\ 0 & 0 & (1-\gamma) \cos \Theta & 0 \\ 0 & 0 & 0 & (1-3 \gamma) \cos \Theta\end{array}\right)$,

where $\gamma=\rho_{n}\left(2-\rho_{n}\right)^{-1}$. The Rayleigh scattering optical thickness in the vertical direction above the height $h$ is given by

$$
\tau^{(s, R)}(h)=\sigma \int_{h}^{\infty} N(z) d z .
$$


From (2) and (5), we see that for a given number of molecules, the molecular anisotropy increases the Rayleigh scattering optical thickness by a factor

$$
\frac{\left(1+\frac{1}{2} \rho_{n}\right)}{\left(1-\frac{7}{6} \rho_{n}\right)}
$$

For air $\rho_{\mathrm{n}}=0.0303$ (Gïcker et al., 1969). The molecular anisotropy thus increases the Rayleigh scattering optical thickness by a factor of 1.052 .

The Rubenson degree of polarization $P$, in the principal plane, is given by

$$
P=\left(I_{r}-I_{\ell}\right) /\left(I_{r}+I_{\ell}\right)
$$

The principal plane for the plane-parallel atmospheric models that are used here is perpendicular to the parallel planes and contains the sun, which is assumed to be a point source. The degree of polarization of single scattering of the neutral sunlight is obtained by substituting (4) in (I) and then putting the resulting $I_{r}^{s}$ and $I_{\ell}^{s}$ in $(7)$ :

$$
P=\frac{\sin ^{2} \Theta(1-y)}{1+\cos ^{2} \Theta+y\left(2+\sin ^{2} \Theta\right)}
$$

Since $\gamma=0.0154$ for the earth's atmosphere, it decreases the numerator and increases the denominator. As a result, molecular anisotropy decreases the degree of polarization in all directions, and the effect is largest at $\Theta=90^{\circ}$, where it decreases the degree of polarization by 0.059 .

The inclination $x$ of the plane of polarization from the $\ell$-direction is given by the equation

$$
x=\frac{1}{2} \arctan \left[\mathrm{U} /\left(\mathrm{I}_{\ell}-\mathrm{I}_{\mathrm{r}}\right)\right]
$$


since $U=V=0$ for the incident sunlight, we see from (1) and (4) that for single scattering $U^{s}=0$. Hence, the plane of polarization of the scattered light is either parallel or perpendicular to the scattering plane and does not depend on the molecular anisotropy.

\section{MODELS AND COMPUTATIONAL DETAILS}

We have carried out computations of the polarization characteristics of light scattered from the following model atmospheres:

A: Rayleigh atmosphere without molecular anisotropy.

B: Rayleigh atmosphere with molecular anisotropy.

C: Rayleigh atmosphere with ozone absorption, nonabsorbing haze, and without molecular anisotropy.

D: Rayleigh atmosphere with ozone absorption, nonabsorbing haze, and molecular anisotropy.

These atmospheres are assumed to be plane-parallel, vertically nonhomogeneous for models $\mathrm{C}$ and $\mathrm{D}$, and illuminated at the top by a unidirectional monochromatic radiation of wavelength $\lambda=0.55 \mu \mathrm{m}$. All orders of scattering are taken into account. The atmospheres are bounded on the bottom by a Lambert reflector with reflectivity A.

For model A, the Rayleigh optical thickness $\tau^{(s, R)}=0.0924$. For model B $\tau^{(s, R)}=0.0973$. For models $\mathrm{C}$ and $\mathrm{D}$ the ozone absorption optical thickness $\tau_{0}^{\text {a }}=0.0269$, and the Mie scattering optical thickness of the particulates is $\tau^{(s, m)}=0.2979$. The total scattering optical thicknesses for models $\mathrm{C}$ and $\mathrm{D}$ are 0.4172 and 0.4221 , respectively, and differ because of molecular anisotropy in model $\mathrm{D}$.

In our computations, we entered the height dependence of the pressure of nonabsorbing gases, the ozone density, and the total number density of particulates for thirty-five heights $(0-70 \mathrm{~km})$ as specified by McClatchey et al., (1971). The model atmosphere is divided into forty layers. In Fig. 1 the solid line curve shows the amount of ozone in a vertical column above a given level for models $\mathrm{C}$ and $\mathrm{D}$. The total amount of ozone above sea level is $0.316 \mathrm{~atm}-\mathrm{cm}$. The dashed line shows the total number of particulates above a level in a vertical column with a cross-sectional area of one $\mathrm{cm}^{2}$. There are $4.91 \times 10^{8}$ particulates per $\mathrm{cm}^{2}$ above sea level. 
CUMULATIVE AMOUNT OF OZONE IN ATM-CM

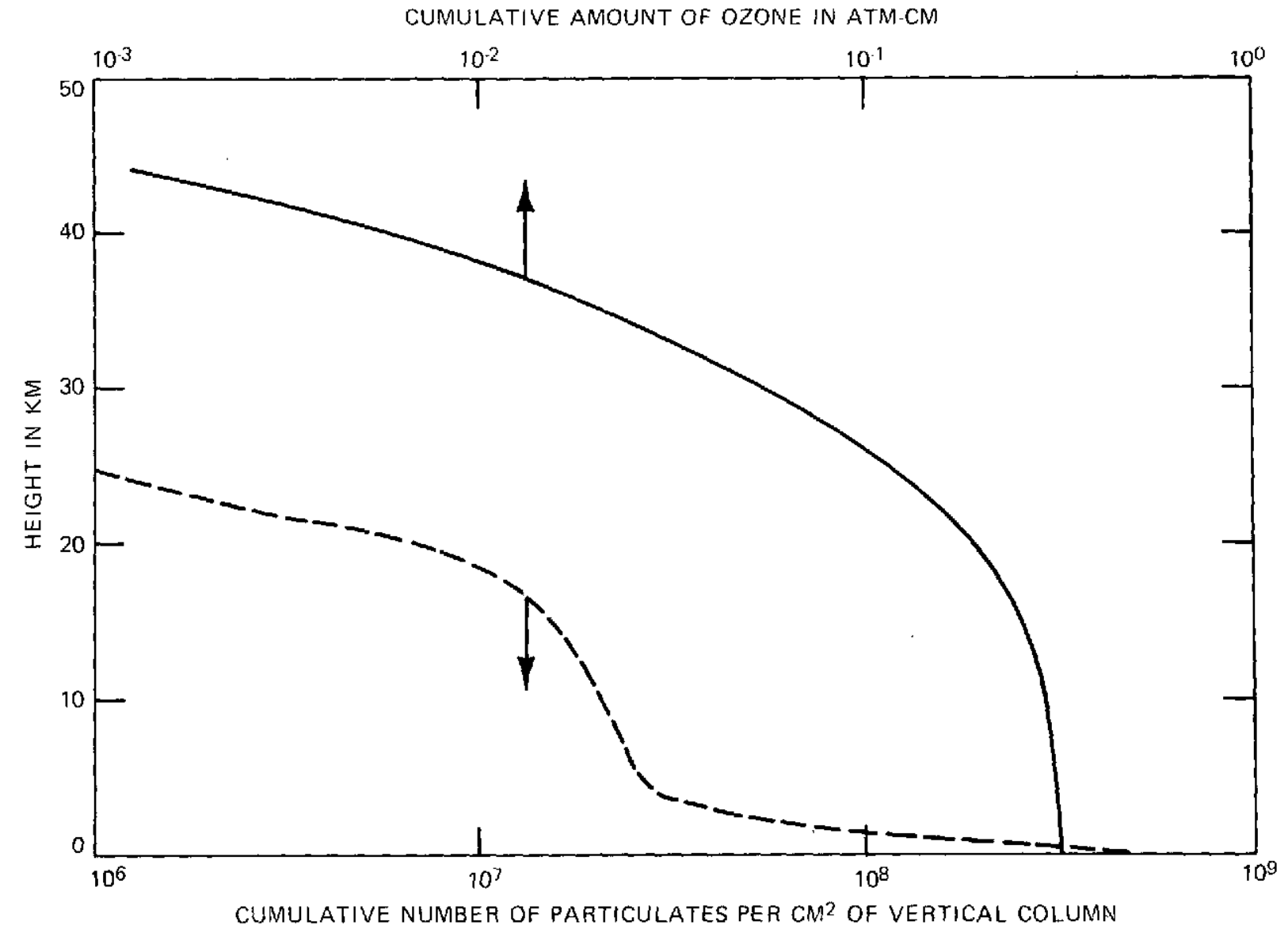

Figure 1. An atmospheric model of the amount of ozone (solid line curve) and the total number of particulates in one square centimeter (dashed line) of a vertical column above a given level. The total ozone amount in a vertical column above sea level is $0.316 \mathrm{~atm}-\mathrm{cm}$ and the total number of particulates is $4.91 \times 10^{8} \mathrm{~cm}^{-2}$. 
For the haze in models $C$ and $D$, we have used a continental distribution of the discontinuous type: the "haze C" model proposed by Deirmendjian (1964). This model simulates the mean size distribution of particulates in continental air masses fairly well and is given by

$$
\frac{\operatorname{dn}(\mathrm{r})}{\mathrm{dr}}= \begin{cases}\mathrm{C} & \text { for } 0.03 \mathrm{~s} \leq 0.1 \mu \mathrm{m} \\ \mathrm{C}\left(\frac{\mathrm{r}}{0.1}\right)^{-4} & \text { for } 0.1<\mathrm{r} \leq 5 \mu \mathrm{m}\end{cases}
$$

where $C$ is a constant; $d n / d r$ represents the number concentration of particulates per cubic centimeter of air per micrometer radius. The particulate number density used in these computations has a strong exponential decrease up to $5 \mathrm{~km}$, a fairly constant value until $15 \mathrm{~km}$, a layer of high concentration at about $20 \mathrm{~km}$, and for increasing heights, it falls of exponentially. A refractive index of $\mathrm{m}=$ $1.5-0.0 \mathrm{i}$ is used for the aerosols.

We have modified Dave's (1972) programs to incorporate the effect due to molecular anisotropy, and the results presented here employ Dave's scheme of representing the phase matrix and Stokes parameters in Fourier series in the azimuth. In all the computations that follow, it is assumed that the flux incident on a horizontal surface at the top of the atmosphere is $\pi \cos \theta_{0}$, where $\theta_{0}$ is the solar zenith angle.

\section{RESULTS AND DISCUSSION}

First, we will discuss the results and comparisons of intensity, flux, degree of polarization, and positions of the neutral points at the top and bottom of the atmospheric models described above, when the effect due to molecular anisotropy is included in the molecular optical thickness as well as in the Rayleigh phase matrix. Later, we will present results for the cases when the molecular optical thickness is kept constant and the molecular anisotropy is included in the Rayleigh phase matrix only.

\section{a) Intensities}

Tables 1 and 2 show the intensity distribution of scattered light in the sun's principal plane at the top and bottom of model atmospheres for zero ground reflectivity and a solar zenith angle of $60^{\circ}$. In the third and sixth rows of these tables, we have shown the relative percentage change due to molecular anisotropy for the Rayleigh and hazy atmospheres. For the Rayleigh atmosphere, the maximum change due to molecular anisotropy is 7.3 percent, whereas for the hazy atmosphere, the maximum change is 3.2 percent at both the top and 
Table 1

Upward intensity at the top of the atmosphere for ground reflectivity $A=0.0$ and for various atmospheric models. $\delta$ gives the percentage change from $\mathrm{A}$ to $\mathrm{B}$, and $\triangle$ gives the percentage change from $C$ to $D$. The wavelength $\lambda=0.55 \mu \mathrm{m}$ and the solar zenith angle $\theta_{0}=60^{\circ}$.

\begin{tabular}{|c|c|c|c|c|c|c|c|c|c|c|}
\hline \multirow{2}{*}{ Model $/ \theta$} & \multicolumn{9}{|c|}{$\phi=0^{\circ}$} & \multicolumn{6}{c|}{$\phi=180^{\circ}$} \\
\cline { 2 - 11 } & $0^{\circ}$ & $20^{\circ}$ & $40^{\circ}$ & $60^{\circ}$ & $80^{\circ}$ & $0^{\circ}$ & $20^{\circ}$ & $40^{\circ}$ & $60^{\circ}$ & $80^{\circ}$ \\
\hline A & 0.0218 & 0.0192 & 0.0236 & 0.0428 & 0.1329 & 0.0218 & 0.0293 & 0.0424 & 0.0673 & 0.1567 \\
B & 0.0230 & 0.0206 & 0.0252 & 0.0451 & 0.1375 & 0.0230 & 0.0306 & 0.0439 & 0.0695 & 0.1609 \\
$\delta$ & 5.5 & 7.3 & 6.8 & 5.4 & 3.5 & 5.5 & 4.4 & 3.5 & 3.3 & 2.7 \\
C & 0.0373 & 0.0402 & 0.0630 & 0.1399 & 0.3859 & 0.0373 & 0.0459 & 0.0693 & 0.1171 & 0.1958 \\
D & 0.0385 & 0.0415 & 0.0643 & 0.1407 & 0.3822 & 0.0385 & 0.0472 & 0.0707 & 0.1187 & 0.1983 \\
$\Delta$ & 3.2 & 3.2 & 2.1 & 0.6 & -1.0 & 3.2 & 2.8 & 2.2 & 1.4 & 1.3 \\
\hline
\end{tabular}

Table 2

Downward intensity at the bottom of the atmosphere for the same conditions given in Table 1.

\begin{tabular}{|c|c|c|c|c|c|c|c|c|c|c|}
\hline \multirow{2}{*}{ Model/ $\theta$} & \multicolumn{4}{|c|}{$\phi=0^{\circ}$} & \multicolumn{6}{c|}{$\phi=180^{\circ}$} \\
\cline { 2 - 10 } & $0^{\circ}$ & $20^{\circ}$ & $40^{\circ}$ & $60^{\circ}$ & $80^{\circ}$ & $0^{\circ}$ & $20^{\circ}$ & $40^{\circ}$ & $60^{\circ}$ & $80^{\circ}$ \\
\hline A & 0.0217 & 0.0292 & 0.0422 & 0.0669 & 0.1545 & 0.0217 & 0.0192 & 0.0235 & 0.0426 & 0.1311 \\
B & 0.0230 & 0.0305 & 0.0438 & 0.0691 & 0.1584 & 0.0230 & 0.0205 & 0.0251 & 0.0449 & 0.1353 \\
$\delta$ & 6.0 & 4.5 & 3.8 & 3.3 & 2.5 & 6.0 & 6.8 & 6.8 & 5.4 & 3.20 \\
C & 0.0718 & 0.1426 & 0.3752 & 3.146 & 0.9677 & 0.0718 & 0.0496 & 0.0501 & 0.0729 & 0.1251 \\
D & 0.0727 & 0.1429 & 0.3735 & 3.116 & 0.9591 & 0.0727 & 0.0509 & 0.0517 & 0.0749 & 0.1269 \\
$\Delta$ & 1.3 & 0.2 & -0.4 & -1.0 & -0.9 & 1.3 & 2.6 & 3.2 & 2.7 & 1.4 \\
\hline
\end{tabular}


the bottom of the atmosphere. Of course, the molecular anisotropic effect on a hazy atmosphere depends on the haze model. The maximum changes occur near to where the observation angle is $90^{\circ}$ from the sun line, which occurs at $\theta=30^{\circ}, \phi=0^{\circ}$ at the top, and $\theta=30^{\circ}, \phi=180^{\circ}$ at the bottom of the atmosphere. Tables 3 and 4 are similar to Tables 1 and 2, except for a ground reflectivity $\mathrm{A}=0.50$. For a Rayleigh atmosphere, we find that the maximum changes due to molecular anisotropy are 0.6 percent at the top and 6.3 percent at the bottom of the atmosphere. For the hazy atmosphere, the maximum absolute changes due to molecular anisotropy are 0.9 percent at the top and 2.8 percent at the bottom of the atmosphere. The intensity of the outward light at the top of optically thin atmospheres lying above a bright surface is only weakly affected by molecular anisotropy, since most of the light comes directly from the ground, except near to the horizon where the path radiance is stronger than the radiance of the light transmitted directly from the surface. On the other hand, molecular anisotropy still has a significant effect on the skylight reaching the ground.

\section{b) Fluxes}

The flux of the diffuse light through a horizontal surface is given for the various models in Table 5 as a percentage of the solar flux incident on the top of the atmosphere. The two columns labeled top give the total upward flux at the top of atmosphere, and the columns labeled bottom give the downward flux of scattered light at the base of atmosphere. The effect of molecular anisotropy is to increase the fluxes because of the larger optical thickness. The effect is less for a hazy atmosphere than for a molecular one. The surface reflection decreases the effect at the top of the atmosphere but not at the bottom.

\section{c) Polarizations}

Figures 2 and 3 show the degree of polarization of the diffuse light as a function of receiver nadir and zenith angles, respectively. The usual features are apparent: a polarization maximum occuring near $90^{\circ}$ from the sun; the Babinet neutral point lying between the zenith and sun at the bottom, and between the nadir and antisolar point at the top; the Brewster neutral point appearing between the horizon and sun at the bottom, and between the horizon and antisolar point at the top; and finally, the Arago neutral point appearing at the bottom near the horizon, but opposite to the side containing the sun. Only two neutral points appear at the bottom at one time. The maximum changes in the degree of polarization due to molecular anisotropy are 6.9 percent for a Rayleigh atmosphere (curves $A$ and $B$ ), and 3.5 percent for a hazy atmosphere (curves $C$ and $D$ ). The effect of ground reflectivity $(A=0.25)$ on the degree of polarization for a hazy atmosphere with molecular anisotropy is illustrated by curve $\mathrm{E}$. 
Table 3

Upward intensity at the top of the atmosphere for the same conditions given in Table 1, except that the ground reflectivity $\mathrm{A}=0.50$.

\begin{tabular}{|c|c|c|c|c|c|c|c|c|c|c|}
\hline \multirow{2}{*}{ Model/ } & \multicolumn{4}{|c|}{$\phi=0^{\circ}$} & \multicolumn{6}{c|}{$\phi=180^{\circ}$} \\
\cline { 2 - 10 } & $0^{\circ}$ & $20^{\circ}$ & $40^{\circ}$ & $60^{\circ}$ & $80^{\circ}$ & $0^{\circ}$ & $20^{\circ}$ & $40^{\circ}$ & $60^{\circ}$ & $80^{\circ}$ \\
\hline & 0.2494 & 0.2462 & 0.2482 & 0.2608 & 0.3214 & 0.2494 & 0.2563 & 0.2669 & 0.2852 & 0.3451 \\
$\mathrm{~A}$ & 0.2495 & 0.2464 & 0.2486 & 0.2616 & 0.3234 & 0.2495 & 0.2564 & 0.2672 & 0.2859 & 0.3469 \\
$\mathrm{~B}$ & 0.0 & 0.1 & 0.2 & 0.3 & 0.6 & 0.0 & 0.0 & 0.1 & 0.2 & 0.5 \\
$\mathrm{C}$ & 0.2258 & 0.2269 & 0.2432 & 0.3024 & 0.4902 & 0.2258 & 0.2325 & 0.2495 & 0.2796 & 0.3001 \\
$\mathrm{D}$ & 0.2261 & 0.2271 & 0.2435 & 0.3022 & 0.4856 & 0.2261 & 0.2329 & 0.2499 & 0.2802 & 0.3017 \\
$\Delta$ & 0.1 & 0.1 & 0.1 & -0.1 & -0.9 & 0.1 & 0.2 & 0.2 & 0.1 & 0.5 \\
\hline
\end{tabular}

Table 4

Downward intensity at the bottom of the atmosphere for the same conditions given in Table 3 .

\begin{tabular}{|c|c|c|c|c|c|c|c|c|c|c|}
\hline \multirow{2}{*}{ Model/ $\theta$} & \multicolumn{9}{|c|}{$\phi=0^{\circ}$} & \multicolumn{6}{c|}{$\phi=180^{\circ}$} \\
\cline { 2 - 10 } & $0^{\circ}$ & $20^{\circ}$ & $40^{\circ}$ & $60^{\circ}$ & $80^{\circ}$ & $0^{\circ}$ & $20^{\circ}$ & $40^{\circ}$ & $60^{\circ}$ & $80^{\circ}$ \\
\hline A & 0.0322 & 0.0404 & 0.0558 & 0.0871 & 0.2042 & 0.0322 & 0.0303 & 0.0371 & 0.0627 & 0.1807 \\
B & 0.0340 & 0.0422 & 0.0579 & 0.0901 & 0.2100 & 0.0340 & 0.0322 & 0.0393 & 0.0659 & 0.1869 \\
$\delta$ & 5.6 & 4.5 & 3.8 & 3.4 & 2.8 & 5.6 & 6.3 & 5.9 & 5.10 & 3.4 \\
C & 0.0876 & 0.1598 & 0.3977 & 3.184 & 1.056 & 0.0876 & 0.0668 & 0.0727 & 0.1106 & 0.2133 \\
D & 0.0890 & 0.1606 & 0.3965 & 3.154 & 1.048 & 0.0890 & 0.0685 & 0.0747 & 0.1126 & 0.2156 \\
$\triangle$ & 1.6 & 0.5 & -0.3 & -1.0 & -0.8 & 1.6 & 2.5 & 2.8 & 1.8 & 1.1 \\
\hline
\end{tabular}


Table 5

Upward flux at the top and the diffuse downward flux at the bottom of the atmosphere as a percentage of the incident solar flux received at the top. The molecular anisotropy effect is included in the Rayleigh optical thickness as well as in the Rayleigh phase matrix. The wavelength $\lambda=0.55$ $\mu \mathrm{m}$, solar zenith angle $\theta_{0}=60^{\circ}$ and surface reflectivities are $A=0.0$ and 0.5 .

\begin{tabular}{|c|c|c|c|c|}
\hline \multirow{2}{*}{ Model } & \multicolumn{3}{|c|}{ Top } & \multicolumn{2}{c|}{ Bottom } \\
\cline { 2 - 5 } & $\mathrm{A}=0.0$ & $\mathrm{~A}=0.50$ & $\mathrm{~A}=0.0$ & $\mathrm{~A}=0.50$ \\
\hline $\mathrm{A}$ & 8.43 & 52.31 & 8.36 & 12.10 \\
$\mathrm{~B}$ & 8.84 & 52.43 & 8.76 & 12.66 \\
$\delta$ & 4.9 & 0.2 & 4.8 & 4.6 \\
$\mathrm{C}$ & 15.95 & 49.71 & 34.03 & 40.50 \\
$\mathrm{D}$ & 16.28 & 49.87 & 34.15 & 40.74 \\
$\Delta$ & 2.1 & 0.3 & 0.4 & 0.6 \\
& & & & \\
in & \multicolumn{2}{|c|}{ percentage change in going from A to B; $\Delta-$ percentage change } \\
in going from C to D.
\end{tabular}

d) Neutral Points

Table 6 elaborates on the positions of neutral points at the top and bottom of various atmospheric models for ground reflectivities of $A=0.0$ and 0.25 . $A$ comparison of the Rayleigh models A and B shows that the molecular anisotropy shifts the positions of the Babinet and Brewster points by about $0.1^{\circ}$ to $0.2^{\circ}$ away from the sun or antisun position for both surface reflectivities. These results agree with Dave's (1964) conclusion that molecular anisotropy has a weak effect on the neutral points in a Rayleigh atmosphere.

The addition of particulates to a Rayleigh atmosphere causes the Babinet and Brewster neutral points at the top of atmosphere to shift by $12.2^{\circ}$ and $9^{\circ}$ away from the antisolar point, as can be seen by comparing models $\mathrm{A}$ and $\mathrm{C}$ or $\mathrm{B}$ and $D$. At the base of the atmosphere, the neutral points also shift away from the sun. The Brewster point actually disappears and is replaced by an Arago point. The computed result that the addition of haze to a Rayleigh atmosphere causes the neutral points at the bottom of the atmosphere to move away from the sun is contrary to observations (Sekera, 1957; Coulson, 1971). Such a discrepancy merits further investigation. Nevertheless, molecular anisotropy has a negligible effect on the neutral point positions in a hazy atmosphere. 


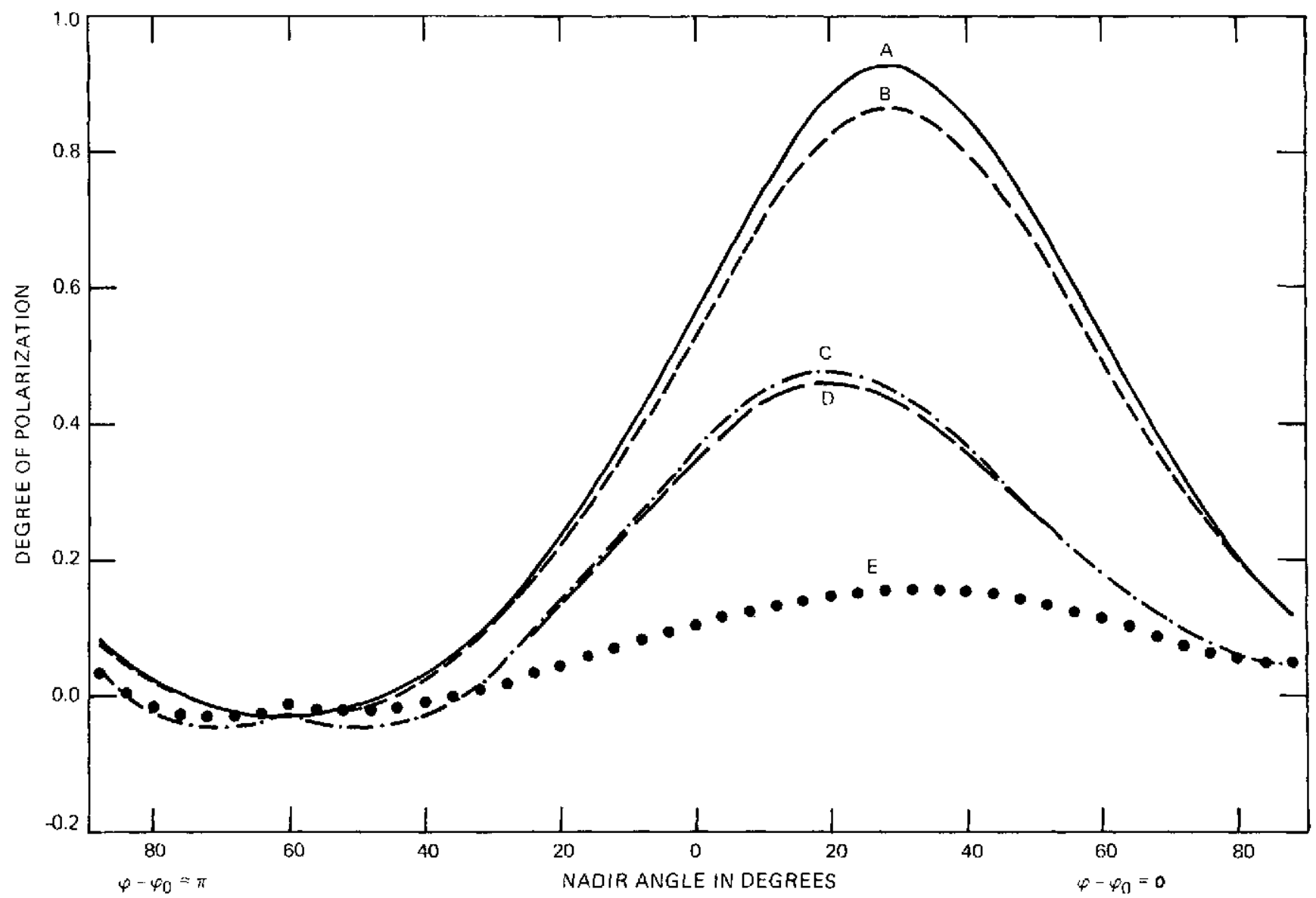

Figure 2. The degree of polarization of light leaving the top of the atmosphere for various models. Wavelength $\lambda=0.55 \mu \mathrm{m}$; solar zenith $\theta_{0}=60^{\circ}$; ground reflectivity $\mathrm{A}=\mathbf{0 . 0}$. Curve $\mathrm{E}$ refers to a model that is the same as model $\mathrm{D}$, except for $\mathrm{A}=\mathbf{0 . 2 5}$. 


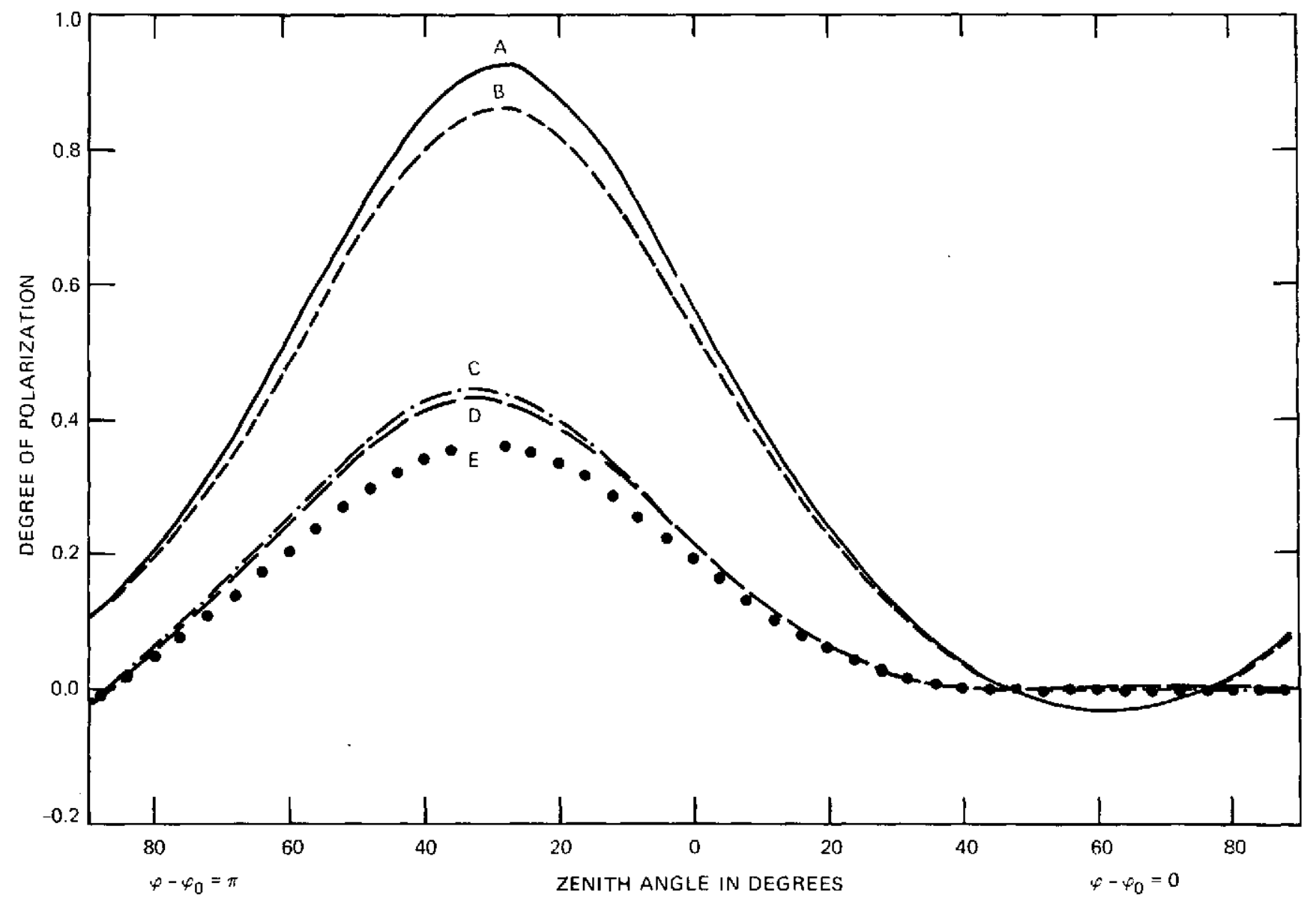

Figure 3. The degree of polarization of skylight at the bottom of the atmosphere for the same conditions given in Figure 2. 
Table 6

The polar angles of the neutral points at the top and bottom of the atmosphere for ground reflectivities $\mathrm{A}=0.0$ and 0.25 for various models. The wavelength $\lambda=0.55 \mu \mathrm{m}$ and the solar zenith angle $\theta_{0}=60^{\circ}$. The molecular anisotropy effect is incorporated in the Rayleigh optical thickness as well as in the Rayleigh phase matrix. The Babinet, Brewster, and Arago points are designated by $\mathrm{Ba}, \mathrm{Br}$, and $\mathrm{Ar}$, respectively.

\begin{tabular}{|c|c|c|c|c|c|c|c|c|c|c|}
\hline \multirow{2}{*}{ Mode1 } & \multicolumn{4}{|c|}{ Top } & \multicolumn{4}{c|}{ Bottom } \\
\cline { 2 - 10 } & \multicolumn{2}{|c|}{$\mathrm{A}=0.0$} & \multicolumn{2}{|c|}{$\mathrm{A}=0.25$} & \multicolumn{3}{c|}{$\mathrm{A}=0.0$} & \multicolumn{3}{c|}{$\mathrm{A}=0.25$} \\
& $\mathrm{Ba}$ & $\mathrm{Br}$ & $\mathrm{Ba}$ & $\mathrm{Br}$ & $\mathrm{Ba}$ & $\mathrm{Br}$ & $\mathrm{Ar}$ & $\mathrm{Ba}$ & $\mathrm{Br}$ & $\mathrm{Ar}$ \\
\hline $\mathrm{A}$ & $46.7^{\circ}$ & $75.4^{\circ}$ & $46.7^{\circ}$ & $75.3^{\circ}$ & $46.7^{\circ}$ & $75.5^{\circ}$ & - & $46.7^{\circ}$ & $75.5^{\circ}$ & - \\
$\mathrm{B}$ & $46.6^{\circ}$ & $75.6^{\circ}$ & $46.6^{\circ}$ & $75.5^{\circ}$ & $46.6^{\circ}$ & $75.7^{\circ}$ & - & $46.6^{\circ}$ & $75.7^{\circ}$ & - \\
$\mathrm{C}$ & $34.5^{\circ}$ & $84.4^{\circ}$ & $34.6^{\circ}$ & $84.0^{\circ}$ & $42.4^{\circ}$ & - & $86.6^{\circ}$ & $42.7^{\circ}$ & - & $86.6^{\circ}$ \\
$\mathrm{D}$ & $34.5^{\circ}$ & $84.4^{\circ}$ & $34.6^{\circ}$ & $84.0^{\circ}$ & $42.4^{\circ}$ & - & $86.6^{\circ}$ & $42.7^{\circ}$ & - & $86.6^{\circ}$ \\
\hline
\end{tabular}




\section{RESULTS FOR PARTIAL CORRECTION DUE TO MOLECULAR ANISOTROPY}

Schiffer (1972) has obtained a solution to the radiative transfer equation by solving an auxiliary equation. In his models for a nonabsorbing gaseous atmosphere, the molecular optical thickness is kept constant and the change due to molecular anisotropy is incorporated in the Rayleigh phase matrix only. We have repeated such calculations for all the four models presented above for the wavelength $\lambda=0.55 \mu \mathrm{m}$, sun zenith $\theta_{0}=40^{\circ}$, and ground reflectivities of $0.00,0.25$, and 0.50 . The Rayleigh scattering optical thickness is $\tau^{(s, R)}=$ 0.0980 in all these models.

Tables 7 and 8 show the computed results of airlight intensities at the top and bottom of various atmospheric models for zero ground reflectivity. In rows three and six of these tables, we have shown the relative percentage change due to molecular anisotropy for the Rayleigh atmosphere ( $A^{\prime}$ and $B^{\prime}$ ) and hazy. atmosphere ( $C^{\prime}$ and $\left.D^{\prime}\right)$. The maximum change in intensity values due to molecular anisotropy is $\mathbf{1 . 6}$ percent for a Rayleigh atmosphere. Tables 9 and 10 are computed for the same conditions of Tables 7 and 8 except for a ground reflectivity of $A=0.5$. The maximum change in intensity due to molecular anisotropy is 1.0 percent for a Rayleigh atmosphere, whereas for a hazy atmosphere, it is 0.4 percent. Table 11 shows that molecular anisotropy has no effect on the total upward and the diffuse downward flux at the top and bottom of the atmosphere.

Figures 4 and 5 show the angular distribution of the degree of polarization at the top and bottom of models for Rayleigh (curves $A^{\prime}$ and $B^{\prime}$ ) and hazy (curves $C^{\prime}$ and $\left.D^{\prime}\right)$ atmospheres with zero ground reflectivity. Curve $E^{\prime}$ is the same as model $D^{\prime}$, except that the ground reflectivity is $A=0.25$. The maximum change due to molecular anisotropy is 6.7 percent for the Rayleigh atmosphere, and for the hazy atmosphere, the change is 5.1 percent at the top and 5.0 percent at the bottom of the atmosphere.

Table 12 shows the positions of neutral points at the top and the bottom of model atmospheres for ground reflectivities $A=0.0$ and 0.25 . Molecular anisotropy causes a negligible change $\left(\sim 0.1^{\circ}\right)$ for the Rayleigh atmosphere (models $A^{\prime}$ and $B^{\prime}$ ). However, Dave (1964) found that the molecular anisotropy shifts the Arago point by $0.5^{\circ}$. For the hazy atmosphere, molecular anisotropy shifts the position of neutral points by about $0.4^{\circ}$ at the top of the atmosphere, but there is no change at the bottom of the atmosphere. 
Table 7

Upward intensity at the top of the atmosphere for a ground reflectivity $A=0$ and various atmospheric models. The wavelength $\lambda=0.55 \mu \mathrm{m}$ and solar zenith angle $\theta_{0}=40^{\circ}$. The molecular anisotropy effect is incorporated only in the Rayleigh phase matrix.

\begin{tabular}{|c|c|c|c|c|c|c|c|c|c|c|}
\hline \multirow{2}{*}{ Model $/ \theta$} & \multicolumn{4}{|c|}{$\phi=0^{\circ}$} & \multicolumn{5}{c|}{$\phi=180^{\circ}$} \\
\cline { 2 - 10 } & $0^{\circ}$ & $20^{\circ}$ & $40^{\circ}$ & $60^{\circ}$ & $80^{\circ}$ & $0^{\circ}$ & $20^{\circ}$ & $40^{\circ}$ & $60^{\circ}$ & $80^{\circ}$ \\
\hline $\mathrm{A}^{\prime}$ & 0.0300 & 0.0253 & 0.0256 & 0.0384 & 0.1129 & 0.0300 & 0.0378 & 0.0489 & 0.0687 & 0.1420 \\
$\mathrm{~B}^{\prime}$ & 0.0298 & 0.0254 & 0.0260 & 0.0390 & 0.1133 & 0.0298 & 0.0373 & 0.0481 & 0.0678 & 0.1410 \\
$\delta^{\prime}$ & -0.7 & 0.4 & 1.6 & 1.6 & 0.4 & -0.7 & -1.3 & -1.6 & -1.3 & -0.7 \\
$\mathrm{C}^{\prime}$ & 0.0469 & 0.0435 & 0.0537 & 0.0982 & 0.2381 & 0.0469 & 0.0617 & 0.0857 & 0.1097 & 0.1711 \\
$\mathrm{D}^{\prime}$ & 0.0467 & 0.0436 & 0.0541 & 0.0988 & 0.2384 & 0.0467 & 0.0612 & 0.0850 & 0.1088 & 0.1703 \\
$\Delta^{\prime}$ & -0.4 & 0.2 & 0.7 & 0.6 & 0.1 & -0.4 & -0.8 & -0.8 & -0.8 & -0.5 \\
\hline
\end{tabular}

$\delta$ 'percentage change in going from $A^{\prime}$ to $B^{\prime} ; \Delta^{\prime}$ percent change in going from $C^{\prime}$ to $D^{\prime}$

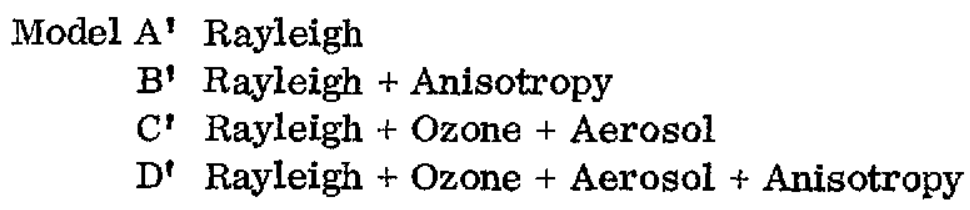

$$
\begin{aligned}
\tau^{(s, R)} & =0.0980 \\
\tau^{(s, R)} & =0.0980 \\
\tau^{\text {Total }} & =0.4225 \\
\tau^{\text {Total }} & =0.4225
\end{aligned}
$$


Table 8

Downward intensity at the bottom of the atmosphere for the conditions of Table 7.

\begin{tabular}{|c|c|c|c|c|c|c|c|c|c|c|}
\hline \multirow{2}{*}{ Model/ $\theta$} & \multicolumn{9}{|c|}{$\phi=0^{\circ}$} & \multicolumn{4}{c|}{$\phi=180^{\circ}$} \\
\cline { 2 - 10 } & $0^{\circ}$ & $20^{\circ}$ & $40^{\circ}$ & $60^{\circ}$ & $80^{\circ}$ & $0^{\circ}$ & $20^{\circ}$ & $40^{\circ}$ & $60^{\circ}$ & $80^{\circ}$ \\
\hline$A^{\prime}$ & 0.0300 & 0.0377 & 0.0488 & 0.0684 & 0.1405 & 0.0300 & 0.0252 & 0.0256 & 0.0382 & 0.1117 \\
$B^{\prime}$ & 0.0298 & 0.0372 & 0.0480 & 0.0675 & 0.1395 & 0.0298 & 0.0254 & 0.0260 & 0.0388 & 0.1122 \\
$\delta^{\prime}$ & -0.7 & -1.3 & -1.6 & -1.3 & -0.7 & -0.7 & 0.8 & 1.6 & 1.6 & 0.4 \\
$C^{\prime}$ & 0.1489 & 0.3534 & 2.670 & 0.6033 & 0.5093 & 0.1489 & 0.0832 & 0.0652 & 0.0764 & 0.1195 \\
$D^{\prime}$ & 0.1488 & 0.3530 & 2.669 & 0.6025 & 0.5088 & 0.1488 & 0.0833 & 0.0652 & 0.0769 & 0.1197 \\
$\Delta^{\prime}$ & -0.1 & -0.1 & 0.0 & -0.1 & -0.1 & -0.1 & 0.1 & 0.0 & 0.7 & 0.2 \\
\hline
\end{tabular}

Upward intensity at the top of the atmosphere for ground reflectivity $A=0.5$ and for the conditions of Table 8 .

\begin{tabular}{|c|c|c|c|c|c|c|c|c|c|c|}
\hline \multirow{2}{*}{ Model/ $\theta$} & \multicolumn{9}{|c|}{$\phi=0^{\circ}$} & \multicolumn{6}{c|}{$\phi=180^{\circ}$} \\
\cline { 2 - 10 } & $0^{\circ}$ & $20^{\circ}$ & $40^{\circ}$ & $60^{\circ}$ & $80^{\circ}$ & $0^{\circ}$ & $20^{\circ}$ & $40^{\circ}$ & $60^{\circ}$ & $80^{\circ}$ \\
\hline $\mathrm{A}^{\prime}$ & 0.3880 & 0.3821 & 0.3785 & 0.3803 & 0.4063 & 0.3880 & 0.3947 & 0.4018 & 0.4106 & 0.4355 \\
$\mathbf{B}^{\prime}$ & 0.3878 & 0.3822 & 0.3789 & 0.3809 & 0.4068 & 0.3878 & 0.3941 & 0.4010 & 0.4097 & 0.4345 \\
$\delta^{\prime}$ & -0.1 & 0.0 & 0.1 & 0.2 & 0.1 & -0.1 & -0.2 & -0.2 & -0.2 & -0.2 \\
$\mathbf{C}^{\prime}$ & 0.3659 & 0.3593 & 0.3585 & 0.3729 & 0.4141 & 0.3659 & 0.3775 & 0.3905 & 0.3843 & 0.3471 \\
$\mathrm{D}^{\prime}$ & 0.3657 & 0.3594 & 0.3589 & 0.3734 & 0.4144 & 0.3657 & 0.3770 & 0.3898 & 0.3834 & 0.3464 \\
$\Delta^{\prime}$ & -0.1 & 0.0 & 0.1 & 0.1 & 0.1 & -0.1 & -0.1 & -0.2 & -0.2 & -0.2 \\
\hline
\end{tabular}


Table 10

Downward intensity at the bottom of the atmosphere for conditions of Table 9.

\begin{tabular}{|c|c|c|c|c|c|c|c|c|c|c|}
\hline \multirow{2}{*}{ Model/ $\theta$} & \multicolumn{9}{|c|}{$\phi=0^{\circ}$} & \multicolumn{4}{c|}{$\phi=180^{\circ}$} \\
\cline { 2 - 10 } & $0^{\circ}$ & $20^{\circ}$ & $40^{\circ}$ & $60^{\circ}$ & $80^{\circ}$ & $0^{\circ}$ & $20^{\circ}$ & $40^{\circ}$ & $60^{\circ}$ & $80^{\circ}$ \\
\hline$A^{\prime}$ & 0.0475 & 0.0563 & 0.0713 & 0.1020 & 0.2225 & 0.0475 & 0.0439 & 0.0481 & 0.0717 & 0.1936 \\
$\mathrm{~B}^{\prime}$ & 0.0473 & 0.0558 & 0.0706 & 0.1010 & 0.2215 & 0.0473 & 0.0440 & 0.0485 & 0.0723 & 0.1941 \\
$\delta^{\prime}$ & -0.4 & -0.9 & -1.0 & -1.0 & -0.4 & -0.4 & 0.2 & 0.8 & 0.8 & 0.3 \\
$\mathrm{C}^{\prime}$ & 0.1767 & 0.3836 & 2.709 & 0.6687 & 0.6603 & 0.1767 & 0.1133 & 0.1045 & 0.1418 & 0.2706 \\
$D^{\prime}$ & 0.1765 & 0.3831 & 2.708 & 0.6679 & 0.6599 & 0.1765 & 0.1135 & 0.1046 & 0.1423 & 0.2708 \\
$\Delta^{\prime}$ & -0.1 & -0.1 & 0.0 & -0.1 & -0.1 & -0.1 & 0.2 & 0.1 & 0.4 & 0.1 \\
\hline
\end{tabular}


Table 11

Upward flux at the top and the downward diffuse flux at the bottom of the atmosphere as a percentage of the incident solar flux received at the top. The molecular anisotropy effect is incorporated in the Rayleigh phase matrix only. The wavelength $\lambda=0.55 \mu \mathrm{m}$, the solar zenith angle $\theta_{0}=40^{\circ}$, and the surface reflectivities are $A=0.0$ and 0.5 .

\begin{tabular}{|c|c|c|c|c|}
\hline \multirow{2}{*}{ Model } & \multicolumn{2}{|c|}{ Top } & \multicolumn{2}{c|}{ Bottom } \\
\cline { 2 - 5 } & $\mathrm{A}=0.0$ & $\mathrm{~A}=0.50$ & $\mathrm{~A}=0.0$ & $\mathrm{~A}=0.50$ \\
\hline $\mathrm{A}^{\prime}$ & 6.00 & 50.93 & 5.96 & 10.01 \\
$\mathrm{~B}^{\prime}$ & 6.00 & 50.93 & 5.96 & 10.01 \\
$\delta^{\prime}$ & 0.0 & 0.0 & 0.0 & 0.0 \\
$\mathrm{C}^{\prime}$ & 10.17 & 47.40 & 27.99 & 35.32 \\
$\mathrm{D}^{\prime}$ & 10.17 & 47.40 & 27.99 & 35.32 \\
$\Delta^{\prime}$ & 0.0 & 0.0 & 0.0 & 0.0 \\
\hline
\end{tabular}

Table 12

The polar angles of the neutral points are given at the top and bottom of the model atmospheres for ground reflectivities $A=0.0$ and 0.25 . The wavelength $\lambda=0.55 \mu \mathrm{m}$ and the solar zenith angle $\theta=40^{\circ}$. The Rayleigh scattering optical thickness is kept constant in all these models, and the effect due to molecular anisotropy is included in the Rayleigh phase matrix only. The Babinent and Brewster points are designated by $\mathrm{Ba}$ and $\mathrm{Br}$, respectively.

\begin{tabular}{|c|c|c|c|c|c|c|c|c|}
\hline \multirow{3}{*}{ Model } & \multicolumn{4}{|c|}{ Top } & \multicolumn{4}{c|}{ Bottom } \\
\cline { 2 - 9 } & \multicolumn{2}{|c|}{$\mathrm{A}=0.0$} & \multicolumn{2}{|c|}{$\mathrm{A}=0.25$} & \multicolumn{2}{c|}{$\mathrm{A}=0.0$} & \multicolumn{2}{c|}{$\mathrm{A}=0.25$} \\
\cline { 2 - 9 } & $\mathrm{Ba}$ & $\mathrm{Br}$ & $\mathrm{Ba}$ & $\mathrm{Br}$ & $\mathrm{Ba}$ & $\mathrm{Br}$ & $\mathrm{Ba}$ & $\mathrm{Br}$ \\
\hline $\mathrm{A}^{\prime}$ & $31.0^{\circ}$ & $50.7^{\circ}$ & $31.0^{\circ}$ & $50.7^{\circ}$ & $31.0^{\circ}$ & $50.8^{\circ}$ & $31.0^{\circ}$ & $50.8^{\circ}$ \\
$\mathrm{B}^{\prime}$ & $31.1^{\circ}$ & $50.7^{\circ}$ & $31.1^{\circ}$ & $50.7^{\circ}$ & $\mathbf{3 1 . 1 ^ { \circ }}$ & $50.7^{\circ}$ & $31.0^{\circ}$ & $50.8^{\circ}$ \\
$\mathrm{C}^{\prime}$ & $16.0^{\circ}$ & $63.9^{\circ}$ & $16.0^{\circ}$ & $63.4^{\circ}$ & $25.5^{\circ}$ & $57.4^{\circ}$ & $25.6^{\circ}$ & $56.8^{\circ}$ \\
$\mathrm{D}^{\prime}$ & $15.6^{\circ}$ & $64.3^{\circ}$ & $15.6^{\circ}$ & $63.9^{\circ}$ & $25.5^{\circ}$ & $57.4^{\circ}$ & $25.6^{\circ}$ & $56.8^{\circ}$ \\
\hline
\end{tabular}




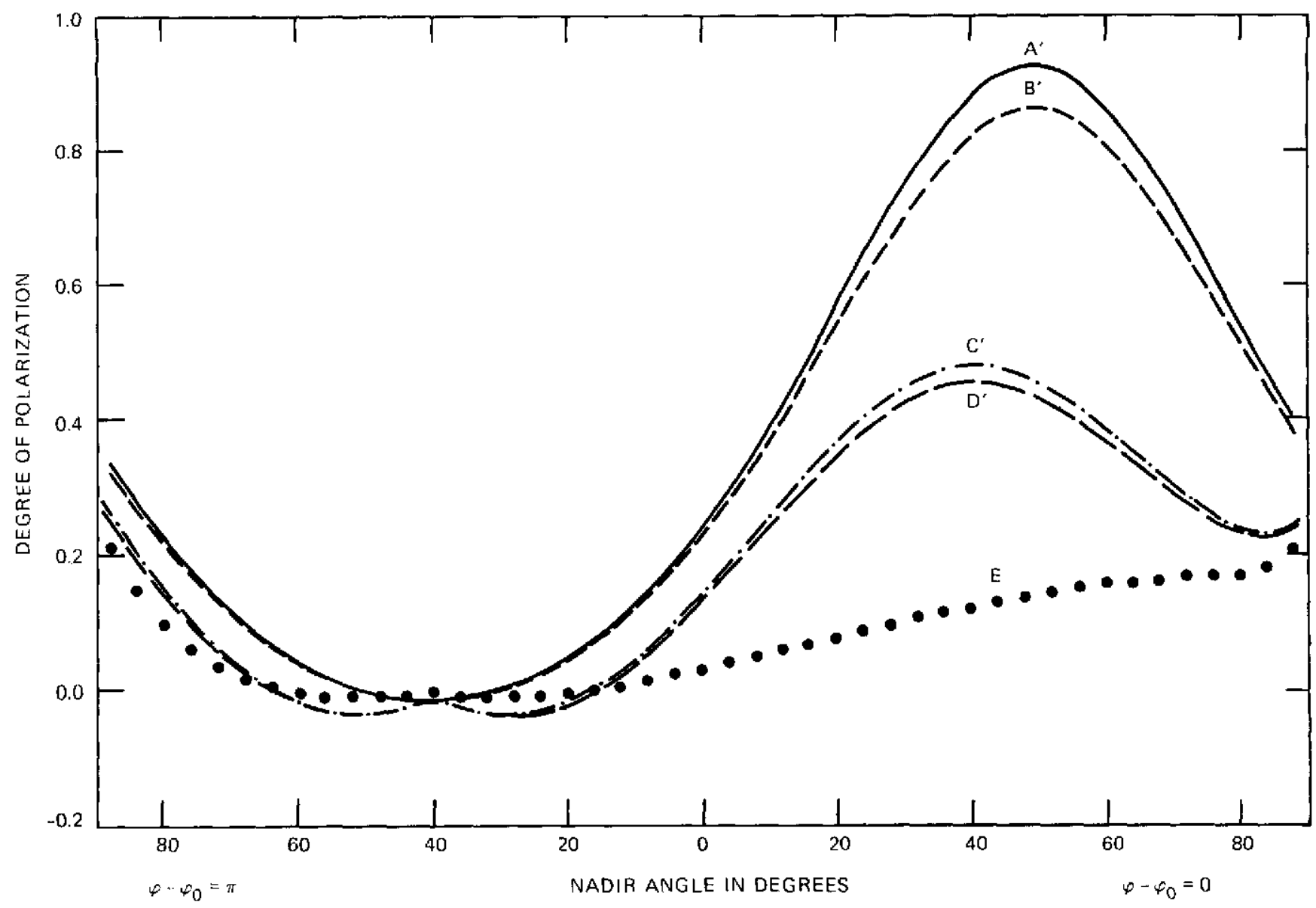

Figure 4. The degree of polarization of light leaving the top of the atmosphere for various models. Wavelength $\lambda=0.55 \mu \mathrm{m}$; solar zenith $\theta_{0}=40^{\circ}$. Curves $A^{\prime}, B^{\prime}, C^{\prime}, D^{\prime}$ and $E^{\prime}$ are similar to those of Figure 2 except the correction due to molecular anisotropy is included only in the Rayleigh scattering phase matrix. The Rayleigh scattering optical thickness is 0.0980 in all these models. 


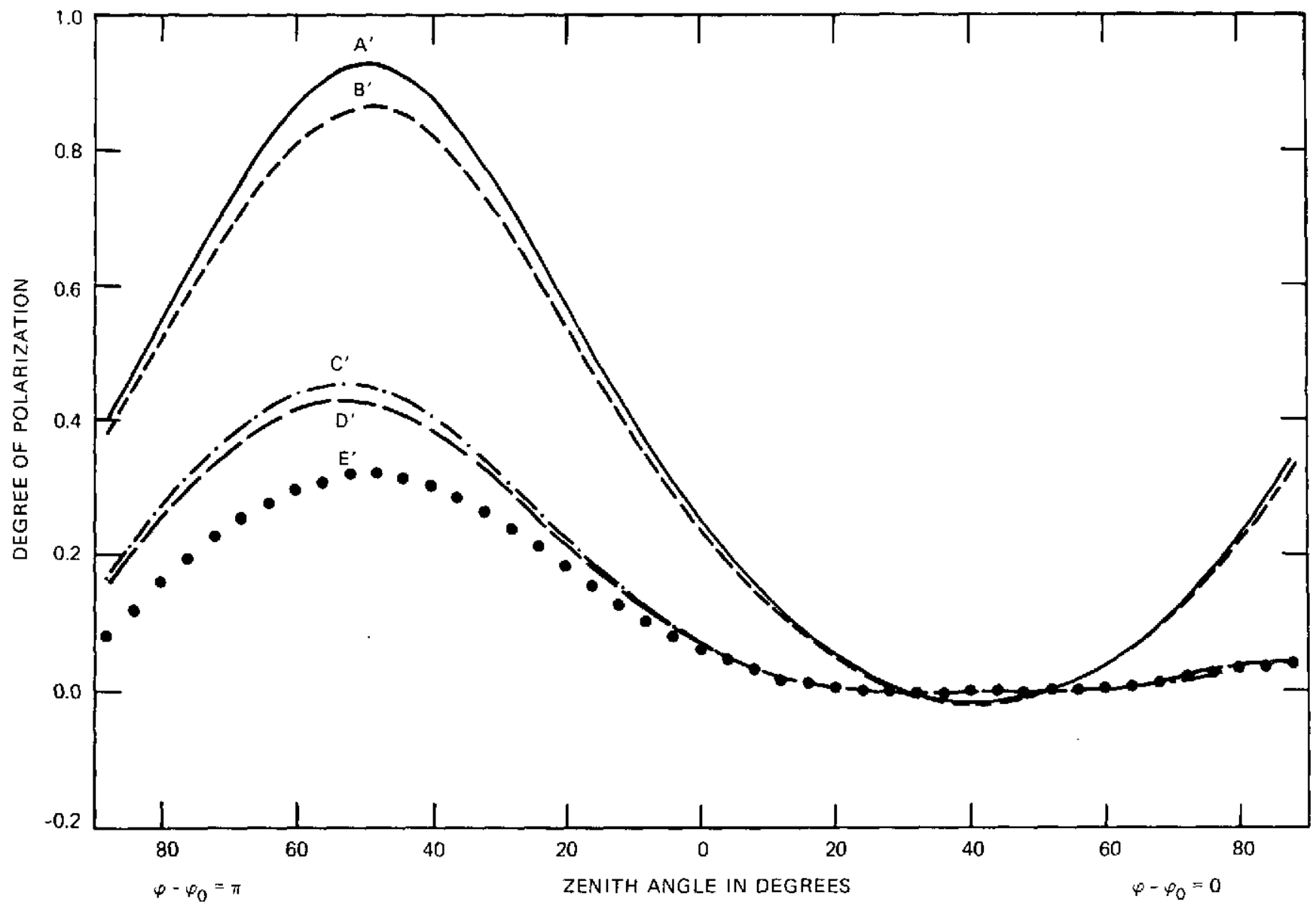

Figure 5. The degree of polarization of skylight at the bottom of the atmosphere for the same conditions given in Figure 4. 
From these comparisons, we find that the inclusion of molecular anisotropy, in the Rayleigh phase matrix only, causes weaker flux and intensity changes, but about the same change in the degree of polarization when compared with the corresponding models in which the molecular anisotropy effect is included in both the Rayleigh optical thickness and phase matrix.

\section{CONCLUSION}

There are several reasons for accounting for the values of radiation parameters with an accuracy of a few percent or better. For example, one percent changes in the earth's global albedo are believed to be important for climatology (Inadvertent Climate Modification, SMIC). Also, our model computations show that if the mass of the atmospheric aerosols increases 50 percent from a nominal state, the intensity that would be measured by a satellite increases by 10 percent over a dark surface, and the maximum degree of polarization would decrease by a few percent over a somewhat brighter surface. Hence, the above discussion and comparisons make it elear that molecular anisotropy has a significant effect on the intensity, flux, and the degree of polarization of scattered light. The changes in the positions of neutral points are quite small. The changes brought about by incorporating the molecular anisotropy in the Rayleigh optical thickness as well as in the Rayleigh phase matrix are more significant compared to the cases when the Rayleigh optical thickness is kept constant and the change due to molecular anisotropy is included only in the Rayleigh phase matrix. The molecular anisotropy effect depends on the Rayleigh optical thickness, the aerosol model, and the solar zenith angle, but these relationships are not studied here. We conclude that to make a realistic study of radiative transfer in the earth's atmosphere involving scattered sunlight, the molecular anisotropy effect must be included in the Rayleigh optical thickness as well as in the Rayleigh phase matrix. 


\section{REFERENCES}

Braslau, N., and Dave, J. V., Effect of aerosols on the transfer of solar energy through realistic model atmospheres. Part I: Nonabosrbing aerosols, J. Appl. Meterol., 12, 601-615, 1973.

Chandrasekhar, S., Radiative Transfer, Dover Publications, New York, 1960.

Coulson, K. L., On the solar radiation field in a polluted atmosphere, J. Quant. Spectrospc. Radiat. Transfer, 11, 739-755, 1971.

Dave, J. V., Importance of higher order scattering in a molecular atmosphere, J. Opt. Soc. Am., 54, 307-315, 1964.

Dave, J. V., Development of programs for computing characteristics of ultraviolet radiation, IBM Technical Report, Gaithersburg, MD., 1972.

Deirmendjian, D., Scattering and polarization properties of water clouds and hazes in the visible and infrared, Appl. Opt., 3, 187-196, 1964.

Gücker, F. T., Basu, S., Pulido, A. A., and Chiu, G., Intensity and polarization of light scattered by some permanent gases and vapors, J. Chem. Phys., 50, 2526-2535, 1969.

Hansen, J. E., Multiple scattering of polarized light in planetary atmospheres. Part I: The doubling method, J. Atmos. Sci., 28, 120-125, 1971.

Hansen, J. E., and Hovenier, J. W., Interpretation of Venus polarization, J. Atmos. Sci., 31, 1137-1158, 1974.

Herman, B. M., and Browning, S. R., A numerical solution to the equation of radiative transfer, J. Atmos. Sci., 22, 559-566, 1965.

Inadvertent Climate Modification, Report on the Study of Man's Impact on Climate (SMIC), The MIT Press, Cambridge, Massachusetts, 111-112, 1971.

Kattawar, G. W., Plass, G. N., and Catchings, F. E., Matrix operator theory of radiative transfer, 2: scattering from maritime haze, Appl. Opt., 12, 10711084, 1973.

McClatchey, R. A., Fenn, R. W., Selby, J. E. A., Garing, J. S., and Volz, F. E., Optical Properties of the Atmosphere, AFCRL-71-0279, Air Force Cambridge Research Laboratories, Bedford, Mass., 1971. 
Plass, G. N., and Kattawar, G. W., Degree and direction of polarization of multiple scattered light. 2: Earth's atmosphere with aerosol, Appl. Opt., 12, 2866-2879, 1972.

Rao, C. R. N., Takashima, T., and Toolin, R. B., Measurements and interpretation of the polarization of radiation emerging from the atmosphere at an altitude of $28 \mathrm{~km}$ above south-western New Mexico (USA), Quart. J. Roy. Met. Soc., 99, 294-302, 1973.

Schiffer, R. A., A solution to the auxiliary equation of radiative transfer for a planetary atmosphere with molecular anisotropy, Conference on Atmospheric Radiation, Fort Collins, Colo., 1-6, 1972 (Preprint).

Sekera, Z., Recent developments in the study of polarization of skylight, in Advances in Geophysics, 3, Academic Press Inc., New York, 43-104, 1956.

Sekera, Z., Polarization of skylight, Handbuch der Physik, 48, 288 328, 1957.

Sekera, Z., Determination of atmospheric parameters from measurements of polarization of upward radiation by satellite or space probe, Icarus, 6, 349-359, 1967.

Unz, F., Die Konzentration des Aerosol in Troposhäre and Stratosphäre aus Messungen dar Polarisation der Himmelsslrahlung in Zenit, Beiträge zur Physik der Atmosphäre, 42, 1-35, 1969. 